\title{
A Bi-Directional Relation between Menopause and Obesity: Focus on the Main Causes and Associated Metabolic Diseases
}

\author{
Renata Mancini Banin, Meira Maria Forcelini Machado, Monica Marques Telles* \\ Department of Biological Sciences, Universidade Federal de São Paulo, Brazil
}

Submission: July 28, 2017; Published: July 31, 2017

*Corresponding author: Mônica Marques Telles, Department of Biological Sciences, Universidade Federal de São Paulo, Brazil, Tel: 55 114-044-0500; Email: mmtelles75@gmail.com

\begin{abstract}
Menopause is an important physiologic stage that determines the end of female reproductive capacity and which is associated to several physical and psychological changes, interfering directly in the quality of women life. Due to metabolic profile and body composition alterations related to menopause, post-menopausal women become more susceptible to the development of metabolic disorders and obesity. Some menopause-related symptoms are alleviated with the hormone replacement therapy (HRT). However, some side effects are associated with its long-term use including a higher risk of cardiovascular diseases development and breast cancer. Therefore, body weight control through physical exercises and a balanced diet should be stimulated instead of pharmacological therapies.
\end{abstract}

Keywords: Menopause; Obesity; Visceral adiposity; Dyslipidemia; Insulin resistance; Cardiovascular diseases; Body weight control; Hormone replacement therapy

Abbreviations: HRT: Hormone Replacement Therapy; LPL: Lipoprotein Lipase

\section{Introduction}

Menopause is characterized by the permanent end of the female reproductive capacity as a result of the diminished pituitary and hypothalamic hormones release which regulate the menstrual cycle, leading to the ovarian function loss and, consequently, to a cessation of the estrogen and progesterone secretion [1,2]. However, it has been reported that the estrogenic fall is the main factor responsible for the menopausal troubles, such as vaginal dryness, urogenital dysfunctions, vasomotor symptoms, obesity and psychological disturbances, which interfere negatively in the quality of life of these women [3,4]. Taking into consideration that the average age of the menopause onset is around 50 years and the life expectancy for women is about 75 years old, it means that most women will spend about one third of their lives in the postmenopausal period, often suffering its consequences [5].

Many factors are involved in the body weight gain after menopause, such as physical inactivity and natural aging per se, which already promotes a decrease in basal caloric expenditure. However, the estrogenic reduction seems to play an important role in the development of menopause-related obesity. It has been reported that the estrogen deficiency leads to a decrement of the lipolysis rate, leading to the adipose tissue accumulation mainly in the abdominal region $[6,7]$. It is well established that the central adiposity expansion is associated to arterial hypertension, insulin resistance, glucose intolerance and dyslipidemias, a condition known as metabolic syndrome $[7,8]$ whose development is one of the most worrisome consequences of menopause.

Hormone replacement therapy (HRT) remains the most common treatment for menopausal symptoms. Studies have shown that the estrogen therapy significantly improves hot flushes frequency, urogenital atrophy, vaginal dryness, urinary incontinence and mood oscillations, as well as it promotes a better body weight control $[3,5,9]$. Nonetheless, considering that HRT may pose important health risks, such as breast cancer and cardiovascular diseases, it is highly desirable to discover new alternatives in the menopause-related symptoms management, with minor side effects [10].

\section{Discussion}

Although menopause is a physiologic condition that naturally occurs in the woman life, its main consequences deserve an adequate careful. Particularly, menopause-related obesity has become a notable public health problem, which could contribute to a poor lifestyle and an early death [3]. Obesity affects approximately $65 \%$ of women between the ages of 40 and 59 and 
$73.8 \%$ of women over 60 years of age [7]. In addition, body weight gain was also observed in ovariectomized animals, which was related to both the excessive food intake as well as the decrement in body metabolism, leading to a drop in the energy expenditure and in the lipolytic rate of adipose tissue in response to the ovarian interruption [11].

It is important to emphasize that women are naturally more susceptible to present psychiatric eating disorders than men. Thus, during the menopause establishment, the risk of developing obesity and metabolic syndrome triples due to the changes in the body composition and metabolic profile owing to the hormonal oscillation $[6,12,13]$. Even though that the beginning of obesity in menopausal women is still unknown, hypoestrogenism has been pointed to play a pivotal role in the increase of body fat [7]. In normal conditions, estrogen seems to be involved in the body adiposity distribution, promoting fat storage in the subcutaneous adipose tissue, especially in the quadriceps and the gluteus regions $[13,14]$. In addition, this hormone regulates the lipoprotein lipase (LPL) action in white adipose tissue, an enzyme responsible for the circulating triglycerides hydrolysis and, therefore, for the fatty acids absorption into the adipocytes [15]. Estrogens also reduce hepatic and muscular lipogenesis as well as they promote an anorexigenic effect in the hypothalamus [13].

In the postmenopausal period, the reduction on estrogen levels modifies the body fat distribution, increasing visceral fat accumulation and leading to central obesity. In addition, increased visceral fat is accompanied by an unfavorable lipid profile, characterized by higher serum levels of total cholesterol and LDLcholesterol and lower HDL-cholesterol concentration. Finally, the coexistence of central obesity and dyslipidemias accelerates the development of cardiovascular diseases, which is a very common feature in postmenopausal women $[8,16]$.

Furthermore, the abnormal expansion of adipose tissue increases the production and secretion of several proinflammatory cytokines, favoring the establishment of insulin resistance [8]. Postmenopausal women present an abnormal secretion of adipokines, characterized by increased leptin levels and decreased adiponectin concentration, being strongly related to the accumulation of abdominal adipose tissue caused by hypoestrogenism [17]. In fact, it has been shown that postmenopausal obese women exhibited an altered leptin/ adiponectin ratio, which contributes to a state of insulin resistance [18].

It is well recognized that the metabolic disturbances herein highlighted promote health damage and a worsening of the quality of life of postmenopausal women. However, pharmacological treatments should not be the first choice; rather, it is highly desirable to encourage prevention strategies including the adoption of healthier living habits, such as the regular practice of physical activity, a balanced diet, and as well as the avoidance of alcohol consumption [19]. Although HRT is not recommended in the management of the menopause-associated metabolic consequences, it can be considered as an auxiliary therapy agent $[3,8]$.

\section{Conclusion}

In summary, the estrogenic reduction negatively affects the lipid metabolism, which favors obesity and insulin resistance development. Estrogens reduce adiposity by stimulating the use of fatty acids as a source of energy, in addition to stimulating the lipolysis of white adipose tissue. Together, these actions culminate in an adequate regulation of peripheral fat distribution and improvement on insulin sensitivity. Considering that adipose tissue plays a crucial role in glucose homeostasis, the fall in estrogen levels contributes to a loss of glucose metabolism and the development of type 2 diabetes, as well as an abnormal function of adipose tissue. Even though women who adopt HRT show a general improvement in menopausal symptoms, nonpharmacological control of body weight gain remains the most interesting strategy, in order to avoid the unwanted side effects of HRT.

\section{References}

1. Dalal PK, Agarwal M (2015) Postmenopausal syndrome. Indian J Psychiatry 57(Supple 2): S222-S232.

2. Sorpreso IC, Soares Júnior JM, Fonseca Am, Baracat EC (2015) Female aging. Rev Assoc Med Bras 61(6): 553-556.

3. Al Safi ZA, Santoro N (2014) Menopausal hormone therapy and menopausal symptoms. Fertil Steril 101(4): 905-915.

4. Jenabi E, Shobeiri F, Hazavehei SMM, Roshanaei G (2015) Assessment of Questionnaire Measuring Quality of Life in Menopausal Women: A Systematic Review. Oman Med J 30(3): 151-156.

5. Takahashi TA, Johnson KM (2015) Menopause. Med Clin North Am 99(3): 521-534.

6. Asarian L, Geary N (2013) Sex differences in the physiology of eating. Am J Physiol Regul Integr Comp Physiol 305(11): R1215-R1267.

7. Lizcano F, Guzmán G (2014) Estrogen deficiency and the origin of obesity during menopause. Biomed Res Int 2014757461.

8. Stachowiak G, Pertyński T, Pertyńska-Marczewska M (2015) Metabolic disorders in menopause. Prz Menopauzalny 14 (1): 59-64.

9. Santoro N, Epperson CN, Mathews SB (2015) Menopausal Symptoms and Their Management. Endocrinol Metab Clin North Am 44(3): 497515 .

10. Lovre D, Lindsey SH, Mauvais Jarvis F (2016) Effect of menopausal hormone therapy on components of the metabolic syndrome. Ther Adv Cardiovasc Dis.

11. Babaei P, Mehdizadeh R, Ansar MM, Damirchi A (2010) Effects of ovariectomy and estrogen replacement therapy on visceral adipose tissue and serum adiponectin levels in rats. Menopause Int 16(3): 100104.

12. Audet M, Dumas A, Binette R, Dionne IJ (2017) Lifestyle inequalities: explaining socioeconomic differences in preventive practices of clinically overweight women after menopause. Qual Health Res 27(10): 1541-1552. 


\section{Current Research in Diabetes \& Obesity Journal}

13. Kozakowski J, Gietka Czernel M, Leszczyńska D, Majos A (2017) Obesity in menopause-our negligence or an unfortunate inevitability? Prz Menopauzalny 16(2): 61-65.

14. Yamantani H, Takahashi K, Yoshida T, Takata T, Kurachi H (2013) Association of estrogen with glucocorticoid levels in visceral fat in postmenopausal women. Menopause 20(4): 437-442.

15. Messina G, Viggiano A, De Luca V, Messina A, Chieffi S et al. (2013) Hormonal changes in menopause and orexin-A action. Obstetrics and Gynecology International 2013(2013): 1-5.

16. Karvonen Gutierrez C, Kim C (2016) Association of Mid-Life Changes in Body Size, Body Composition and Obesity Status with the Menopausal Transition. Healthcare 4(3): 42
17. Lecke SB, Morsch DM, Spritzer PM (2011) Leptin and adiponectin in the female life course. Braz J Med Biol Res 44(5): 381-387.

18.Xiong Q Hu X, Xu Y, Zhang X, Pan X, et al. (2017) Association of visceral fat area with presence of depressive symptoms in Chinese postmenopausal women with normal glucose tolerance. Menopause.

19. Lobo RA, Davis SR, De Villiers TJ, Gompel A, Henderson VW, et al (2014) Prevention of diseases after menopause. Climacteric 17(5): 540-556.

Your next submission with Juniper Publishers will reach you the below assets

- Quality Editorial service

- Swift Peer Review

- Reprints availability

- E-prints Service

- Manuscript Podcast for convenient understanding

- Global attainment for your research

- Manuscript accessibility in different formats

( Pdf, E-pub, Full Text, Audio)

- Unceasing customer service

Track the below URL for one-step submission https://juniperpublishers.com/online-submission.php 